\title{
The psychoacoustic reality of words
}

\author{
ROSAMOND GIANUTSOS \\ Adelphi University, Garden City, N.Y. 11530
}

While words are divided by blank spaces in print, there is no such obvious convention for separating words in spoken language. An experiment was conducted to ascertain the degree to which less obvious cues are available to signal boundaries between words. Native speakers of English who had no familiarity with Modern Greek listened to tape-recorded speech sequences in Greek into which a brief pause had been inserted. Their job was simply to indicate whether the pause had occurred within one word or between two words. A control group of Greeks exhibited nearly universal agreement. While American Ss responded correctly to just over half the Greek test items, as a group their responses were systematic. It was hypothesized that they were using implicit rules for segmenting English which do not apply to Greek. Suggestions were made as to the exact nature of these rules.

In many written languages, such as English, segmentation is simplified for the reader by the conventional use of blank spaces between words. But in spoken language, no such obvious conventions exist to signal word boundaries acoustically. The possibility remains that less obvious conventions or cues are used. Such cues might be pauses and drops in fundamental frequency and amplitude. The purpose of the experiment described herein is to determine whether or not acoustic cues are used to segment spoken language into words. In other words, an attempt is made to identify the acoustic correlates of the space which divides words in print.

In the search for the semantic units of language, the word is usually abandoned in favor of the morpheme. Nonetheless, the ability to understand the grammar of a sentence depends in part on the ability to segment the sentence into words. For grammatical analysis, the word must still be relied upon as a unit (Bloch \& Trager, 1942). Therefore, the segmentation of verbal input into words is, for the listener, prerequisite to the whole problem of speech comprehension.

To investigate segmentation, Ss were asked to listen to tape-recorded speech sequences into which a brief pause had been inserted. Their job was simply to indicate whether they thought the pause had occurred within one word or between two words.

\section{SUBJECTS}

Two kinds of Ss were used: Experimental Ss comprised the largest group $(\mathrm{N}=40)$. These individuals had a native competence in American English and were completely unfamiliar with Modern Greek. The control group contained 11 individuals who had a native competence in Modern Greek (i.e., Greek was their first-learned language). All the Ss in these groups had some degree of familiarity with American English. Ss in the first (experimental) group ranged in age from late teens to mid-50s and were relatively well educated. The $S s$ in the second (control) group ranged widely as to age and education.

MATERIALS AND APPARATUS

Several passages were selected haphazardly from an introductory text of American English for Greeks (Divry, 1964). Each passage was read as a whole in Greek and in English by native female speakers at a moderate rate for reading out loud and was recorded on a Uher 8000 tape recorder. The tape used in the experiment was made up by recording 10 sequences of two to six words from the original tape onto a Uher $4000 \mathrm{~L}$ tape recorder. Pauses within fragments were made by manually arresting the original tape with the pause key for 2-4 sec. Pauses were not carefully controlled to be equal in length, but care was taken to make them long enough to be unmistakable. Pausing did not appear to cause any marked distortion. Whether or not the pause was placed within or between words was determined randomly (using a random number table), with the single constraint that in each language there were to be an equal number of "within" and "between" trials.

\section{PROCEDURE}

Each of the 10 sequences was recorded onto the master tape, alternately-first in Greek, then in English-making 20 sequences in all. English items were included, although the experiment was intended to compare the performance of both groups on the Modern Greek trials. These sequences also served constantly to remind the Ss of the nature of their task so that they would know what within- and between-word pauses sounded like in their own language.

Each sequence was tested in the following manner: It was first presented twice with no pause. Then there were three test presentations, within each of which a pause was artificially introduced to serve as a marker of a specific locus in the utterance. On each of these tests, the pause was located differently, and Ss indicated on an answer sheet whether or not the pause had occurred at a word boundary. Both groups of Ss listened to the same test tape and received the same instructions. For the native speakers of Greek whose command of English was limited, the instructions were rendered into Greek.

\section{RESULTS}

The 11 native Greek speakers agreed perfectly on all but two test items. On these items, the decision made by 10 Ss was regarded as "correct" or normative; in fact, in each case, the 11 th, dissenting, $S$ had registered uncertainty about his response. All other responses of the native Greeks were considered correct. Using these norms to evaluate the responses of the experimental (non-Greek speaking) group to the Greek fragments, $55 \%$ of the responses were correct, as compared to $50 \%$ by chance. In addition, there was a slight response bias towards saying that pauses did not occur in word boundaries $(p=.56)$.

These responses cannot be assumed to be independent, since each $\mathrm{S}$ was tested 30 times (10 sequences with three different tests/sequence). Therefore, statistical tests cannot be used directly to ascertain whether or not responding was significantly different from chance. The data must be considered separately S-wise and itemwise. Applying the chi-square test to the data S-wise, one finds that an individual $S$ would have to respond correctly less than 10 or more than 20 times on the 30 test items for the two-tailed chance probability to be less than .05. But one can see from Fig. 1-where a frequency distribution for experimental Ss on Greek items is presented-that not one $S$ exceeded these critical values. In other words, no experimental $S$ exceeded chance performance on the Greek items. On the other hand, the data in Fig. 1 show a tendency for Ss to be correct on more than half (15) of the items $(\bar{X}=16.6)$. Further, if one considers the data itemwise, one can find evidence for consistent patterns of responding: if responding were simply random guessing, each item should be responded to correctly by about half of the Ss. However, if more than 24 or fewer than 16 of the 40 ss correctly respond to an item, according to the chi-square test the responding is consistently different from chance $(p<.05)$. From the frequency distribution in Fig. 2, one can see that there were 13 items out of 30 responded to consistently above chance and 9 items consistently below 


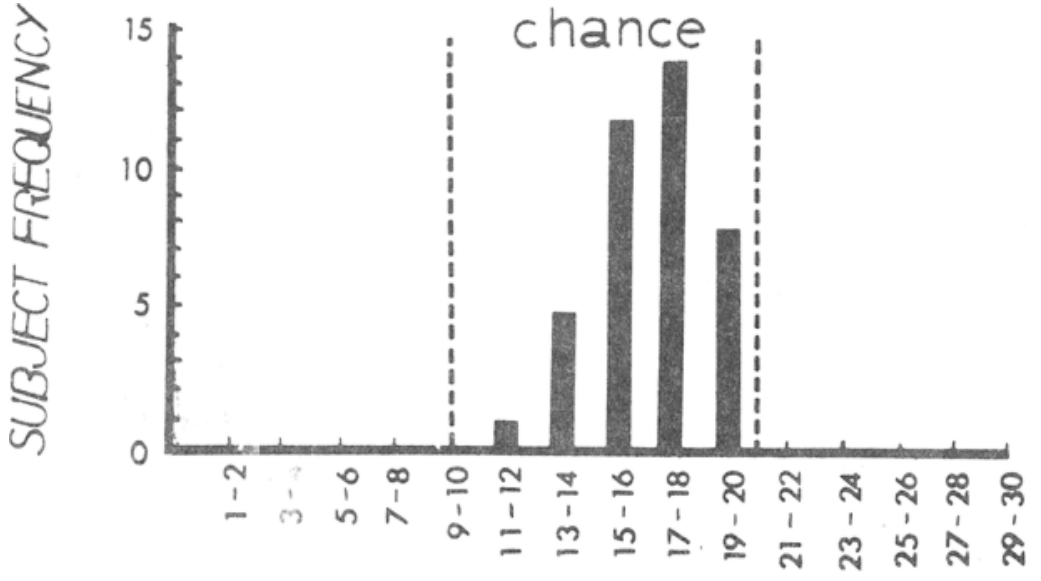

\section{NUMBER OF CORRECT RESPONSES}

Fig. 1. S frequency distribution: number of American Ss at different levels of performance on Modern Greek items. The "chance" interval is the range of correct responding expected by guessing alone. chance level. Only 8 items were at chance level. If responding were unsystematic guessing, then Fig. 2 would be normal-shaped and symmetric, centering at 20 . The rectangularity of the distribution reflects a considerable amount of consistent responding, both "correct" and "incorrect." It is clear from these data that $S s$ make systematic decisions, be they right or wrong, about word boundaries in foreign speech.

\section{DISCUSSION}

The purpose of using Greek sequences was to eliminate all semantic and, for that matter, syntactic expectations, thereby uncovering any possible phonological ones. The possibility that phonological correlates do exist but are not the same for the two languages (implying that errors by Americans on the Greek sequences are due to negative transfer from English) is supported by the rectangularity of the distribution of item proportions.

The exact nature of the English phonological rules for speech segmentation is suggested by content analysis of those items on which responding was systematic. One rule appears to involve patterns of stress. It must be assumed that (1) foreign speech can be divided perceptually into syllables, and (2) one of at least two levels of stress, high and low, can be assigned to each syllable. Decisions about word boundaries may then be made based on the fact that, in polysyllabic English words, the first syllable is usually stressed. Accordingly, if a test pause immediately follows a stressed syllable and precedes an unstressed syllable, then in English it is likely to be a a vowel and another vowel or continuant, Americans will assume the pause splits a word. In 11 instances, the average proportion "within" responses was .77. Three of these instances could also have been accounted for by the stress rule.

This second rule may be overridden by inserting a prevocalic glottal stop. Actually, the glottal stop is a common optional device used in English for dividing words. For example, it is used to distinguish an ice man from $a$ nice man. In the one test involving a glottal stop, responding was $100 \%$ "between."

With a view towards future research, it would be of interest to examine what additional phonological cues are provided when the listener is assumed to have a limited knowledge of the language. For example, for very young children, the segmentation problem is solved in part by restricting the number of words in each breath group. At first, the child responds to whole breath groups (or intonation patterns). There is also a heavy dependence on nonlinguistic cues. The course of postbabbling speech production begins with the one-word naming stage. At the two-word level, the development of elementary grammatical categories based on rules of co-occurrence (Braine, 1963; Brown \& Bellugi, 1964) probably coincides with learning of lexical units. On the other hand, adults acquiring a second language rarely start with such short utterances and elementary grammatical categories. These people may very well have to be provided with phonological cues, such

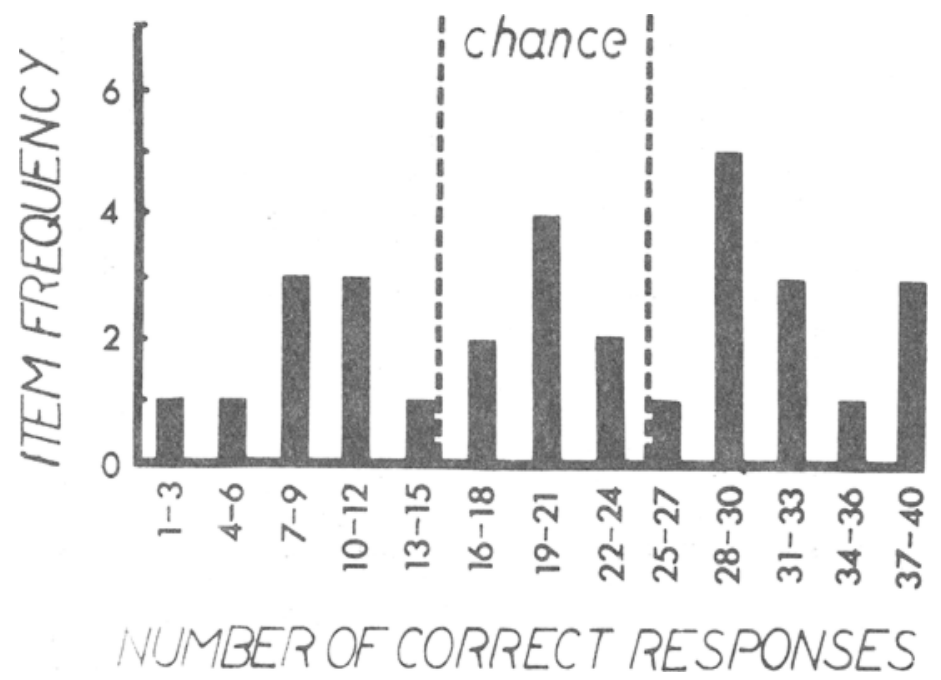

Fig. 2. Item frequency distribution: number of Greek items having different numbers of American Ss responding correctly. At the extreme left are items consistently responded to incorrectly, and at the right are consistently correct items. The chance interval reflects the assumption that if Ss are only guessing, then about half of them will be correct on any particular item. 
as pauses. Investigation of the phonological features of word boundaries in communication situations where the listener has only a limited competency in the language should illuminate important differences between first and second language acquisition.

\section{REFERENCES}

BLOCH, B., \& TRAGER, G. L, Outline oflinguistic analysis. Baltimore: Linguistic Society of America, 1942.

BRAINE, M. D. S. The ontogeny of English phrase structure: The first phrase. Language. $1963,70,323-348$.

BROWN, R. W., \& BELLUGI, U. Three processes in the child's acquisition of syntax. Harvard Educational Review, $1964,34,133-151$.

DIVRY, D. C. New self-taught English method for Greeks. New York: D. C. Divry, 1964. 